\title{
O processo expansionista de educação sob o ideário de privatização
}

\author{
Isabela Fernanda Barros Silva ${ }^{1}$
}

Palavras-chave: educação, política pública, privatização, democratização.

O presente artigo se inscreve no campo das políticas sociais, com recorte na Política de Educação, no âmbito do Programa Universidade para Todos (PROUNI), implementado durante a Reforma Universitária do Governo Lula, que abarcava o discurso de democratização do acesso ao ensino. Entende-se que tais políticas estão pautadas na lógica expansionista do mercado, e são utilizadas como instrumento do Estado para efetivar suas ações. Nesse contexto, observa-se uma nova regulação dentro dos moldes capitalistas para as políticas de educação, que tendem ao direcionamento de um crescimento das instituições privadas em detrimento de uma precarização evidente do investimento em educação na universidade pública e na valorização da carreira do magistério superior.

As transformações sofridas pelo capitalismo contemporâneo acentuam sua lógica de expropriação da força de trabalho e são expressas nas dimensões político-econômicas, ideocultural e social. Assinalada por uma época de superprodução e um momento de estagnação da economia sobre uma profunda recessão, que se combinou como as baixas taxas de crescimento e inflação, durante a década de 90, o Estado reconfigura-se e demonstra a sua incapacidade de controle por meio do intervencionismo.

Iamamoto (2009) considera o Estado como centro de exercício do poder político e que está intimamente relacionado com os diversos segmentos sociais, e desta forma, apresenta um forjado interesse geral. Atenta-se para o fato de que a função do Estado sob a ideologia liberal é simplesmente manutenção da propriedade privada e defesa das garantias patrimoniais e integridade física dos cidadãos. Ainda que se tenha o atendimento da demanda dos trabalhadores nessa lógica estatal, ela é claramente uma função do Estado capturado pela lógica do capital, onde se cria uma imagem social que é necessária para respaldar o momento de acumulação. Ressalta-se que esse processo configura ganhos para o trabalho, mas não na mesma intensidade em que está para o capital, portanto não atende aos interesses antagônicos.

1 Graduada em Serviço Social pela Universidade de Brasília e mestranda do Programa de Política Social da Universidade de Brasília.E-mail: isafbsilva@gmail.com Telefone: (61) 96296505

Categoria do trabalho: artigo. 
Segundo Behring e Boschetti (2011) as políticas sociais tiveram surgimento gradual e diferenciado em cada país, dependendo assim, do movimento no âmbito do Estado e também do grau de desenvolvimento das forças produtivas para se consolidar. Pereira (2000) retrata o apogeu da política social no Welfare State com origem no século XIX na Europa. O surgimento da questão social, a conquista dos direitos políticos e também a ampliação dos direitos sociais, ocorreram entre 1945 e 1975, os 30 anos gloriosos. O Estado capitalista começa então a ser o principal regulador da vida social e passa a ser tensionado por meio da mobilização da classe trabalhadora.

No contexto brasileiro, apesar de se observar alguns avanços na luta da classe trabalhadora sobre benefícios significativos que os amparam durante e após o período militar, estes não se configuravam enquanto políticas sociais. Behring e Boschetti (2011) apontam que se por um lado a criação dos direitos sociais no Brasil resulta da luta de classes, por outro, expressa a legitimação das classes dominantes com um acesso restrito das políticas sociais, com características evidentes pautadas em tutela e favor.

Santos (2012) retrata algumas particularidades no caso brasileiro, onde a "superexploração do trabalho, cujo valor sempre precisou ser mantido bem abaixo dos padrões vigentes em outros países, notadamente os de capitalismo desenvolvido, para que o país continuasse atrativo aos seus investimentos produtivos." (SANTOS, 2012, p.432). Houve também uma intensa repressão dos movimentos sociais e passivização das lutas sociais. Dessa forma, é somente em 1988 que se pode considerar de fato, a consolidação das políticas sociais no Brasil, que, sobretudo, se apresentam de forma tardia, pois é no momento que se tem uma possibilidade efetiva da organização da classe trabalhadora para imprimir essa dinâmica e também quando é possível o Estado ser pressionado para a garantia de direitos.

Diante desse processo, entende-se que a flexibilização e a consequente precarização do trabalho, como afirma Santos (2012) “é erigida no Brasil, como princípio estruturante dos postos de trabalho antes e durante o período fordista do capitalismo brasileiro" (SANTOS, 2012.p.434), ou seja, o Brasil nunca experienciou um Estado de bem-estar pleno, de forma que sua particularidade em relação a outros países se dá neste sentido, uma vez que aqui, nunca vivenciamos a efetivação da ampliação de direitos.

Segundo Netto (1999), a Constituição de 1988 consagrou um profundo avanço social, "ela assentou os fundamentos a partir dos quais a dinâmica capitalista poderia ser direcionada de modo a reduzir, a níveis toleráveis, o que os próprios segmentos das classes dominantes então denominavam 'dívida social"” (NETTO, 1999, p.77). Entretanto, as consequências do ajuste neoliberal para a política social, por sua vez, são enormes, não só porque o aumento do 
desemprego leva ao empobrecimento e ao aumento generalizado da demanda por serviços sociais, mas porque também há a privatização dos serviços, promovendo uma verdadeira antinomia entre política econômica e politica social, para atender aos interesses do capital em uma lógica de produção e reprodução que tende a aumentar o consumo e desviar os recursos públicos para pagamentos de dívidas externas. (BEHRING, 2008).

Diante disso, houve a necessidade de uma nova adequação estatal aos moldes neoliberais ${ }^{2}$, que fez com que houvesse uma nova refuncionalização do Estado, agora reduzido para o social e maximizado para os interesses do mercado. (NETTO, 1992). Observa-se o seu papel subsidiário e a abertura de novas possibilidades de controle através da terceirização dos serviços, da precarização e da exploração da força de trabalho. Dessa forma, há uma erosão dos direitos trabalhistas e sociais, que afeta de forma incisiva todas as outras dimensões da vida humana.

É válido lembrar que atendendo a demandas desta lógica de mercado, e em meio às crises que se expressam em nosso país, o direito à educação previsto na Constituição Federal de 1988, como um direito social, é apenas garantido de forma gratuita e obrigatória para o ensino fundamental, enquanto para o ensino médio fala-se em "progressiva universalização". Atentando-se para o nível superior, ele não é considerado um nível obrigatório de ensino. Dessa forma, um direito social, que deveria ser amplamente coberto por meio das ações de Estado, é assegurado de forma restrita e seletiva, em detrimento de uma educação pública e gratuita. Sobretudo ao que tange as ações estatais, o Estado foi se retirando cada vez mais sua responsabilidade em prover os direitos sociais e dentro dessa perspectiva, a educação pública, passa por um processo de naturalização da privatização das Instituições de Nível Superior. Corroboram com essa reflexão, Yannoulas e Oliveira (2013), ao destacar que:

O Estado brasileiro concentrou seus esforços na elaboração de estratégias para diminuir sua participação no financiamento e no fornecimento direto de serviços educacionais, mas exercendo cada vez mais o controle dos resultados dos serviços educacionais. Esse tipo de controle é incentivado por alguns organismos internacionais que atuam como financiadores de políticas, os quais, sob o pretexto de ajuda financeira, interferem nas políticas nacionais de educação, além de agirem como agentes na globalização do conhecimento e do capitalismo. (YANNOULAS; OLIVEIRA. 2013.p.84).

Sendo a privatização o elemento articulador de estratégias, que atende ao objetivo econômico de abrir todas as atividades econômicas rentáveis aos investimentos privados, há o intuito de ampliar a acumulação e a mercantilizar o bem-estar social. Com o aumento

2 As políticas neoliberais defendem a desresponsabilização estatal pelos direitos sociais. Dessa forma, há uma redução com os gastos públicos, aumento da privatização e consequente acirramento da competitividade pelo mercado. 
progressivo do setor privado e a mínima intervenção estatal sobre os direitos sociais, há um questionamento a respeito do processo existente sob a nova configuração da intervenção estatal em detrimento da mercantilização da saúde, da educação e outros direitos sociais no Brasil.

Em face de um processo de mudança nas configurações das políticas sociais notadamente determinadas pela ideologia neoliberal, a educação vem sendo expressamente apropriada por essa lógica em um processo de privatização dos direitos sociais conquistados e instituídos como universais pela Carta Magna de 1988. Vale, todavia, lembrar que o acesso a direitos sociais, como a educação e a saúde se tornaram um campo lucrativo e de expansão de renda para grande parte da burguesia por meio da prestação de serviços por empresas privadas, em um amplo processo de contrarreformas ${ }^{3}$.

Nesse sentido, a contrarreforma sobre a educação no interior das tensões do desenvolvimento e crise do capitalismo revela um caráter subordinado à lógica capitalista, em um sistema de fragmentação e segmentação da educação enquanto um campo social de disputa hegemônica. Em conformidade, Mészáros (2002) ressalta que: "uma das funções principais da educação formal nas nossas sociedades é produzir tanta conformidade ou consenso quanto for capaz, a partir de dentro e por meio dos seus próprios limites institucionalizados e legalmente sancionados.” (MÉSZÁROS, 2002.p.45).

Em meio aos desafios postos às políticas sociais no atual estágio do desenvolvimento capitalista, a política de educação assume diferentes conteúdos na forma societária capitalista e embora seja potencialmente uma necessidade histórica de uma luta consciente que necessita de condições objetivas e subjetivas de organização e, direção, para alcançar seu intento, está à mercê de um conjunto de reformas e impossibilidades nesse sistema. Iamamoto (2001) observa que a Contistuição de 1988 traz argumentos que muito contribuem para lógica liberal do nosso páis e que "subordina os direitos sociais à lógica orçamentária, a política social à política econômica, em especial às dotações orçamentárias e, no Brasil, subver o preceito constitucional." (IAMAMOTO, 2001. p. 24).

A partir da década de 1990 - a politica educacional ganha nova proporções e, favorecida pelo desenvolvimento tecnológico, outras estratégias de legitimação da

\footnotetext{
3 Termo utilizado para caracterizar o processo de desestruturação do Estado e a perda de direitos. Para Behring (2003, p.213), "na perda da soberania-com aprofundamento da heteronomia e da vulnerabilidade externa; no reforço deliberado da incapacidade do Estado para impulsionar uma política econômica que tenha em perspectiva a retomada do emprego e do crescimento, em função da destruição dos seus mecanismos de intervenção neste sentido, o que implica uma profunda desestruturação produtiva e no desemprego; e, em especial, na parca vontade política e econômica de realizar uma ação efetiva sobre a iniqüidade, no sentido de sua reversão, condição para uma sociabilidade democrática”.
} 
privatização são construídas. Nessa conjuntura, diversas são as indagações quanto às modificações que ocorrem nas estruturas capitalistas que alteram a relação existente entre os direitos sociais e as políticas sociais, em um sistema de constantes alterações em função da barbárie social, na medida em que o Estado reduz a sua atuação e abre-se para o setor privado, eximindo sua responsabilização.

Entretanto, compreende-se a Política de Educação enquanto um direito social que deve ser universalizado. Um conceito amplo, entre a concretização dos direitos sociais e humanos e também, a constituição de "uma seguridade social não formal e restrita, mas constitutiva desse amplo processo de formação de autoconsciência que desvela, denuncia e busca superar as desigualdades sociais que fundam a sociedade do capital e que se agudizam de forma violenta.” (CFESS, 2013.p.22). A partir do exposto, é possível perceber a política social enquanto arena de disputa desde sua gênese, e de fato, ela é dialeticamente contraditória. Diante disso, Almeida (2011), explica:

A educação organizada sob a forma de política pública se constituiu em uma das práticas sociais mais amplamente disseminadas de internalização dos valores hegemônicos na sociedade capitalista. [...] Deste modo, compreender a trajetória da política educacional é um esforço que requer mais do que o resgate de uma história marcada por legislações e mudanças institucionais intestinas, mas de suas relações com a dinâmica e as crises da sociedade do capital, a partir de sua singular inscrição nos processos de estabelecimento de consensos e de reprodução da força de trabalho na realidade brasileira (ALMEIDA, 2011.p.12).

Em face do exposto, a educação se expressa como uma estratégia de intervenção do Estado, em meio a um paradoxo, que ao mesmo tempo em que atende as demandas do capital necessárias a sua reprodução, também é o meio pelo qual há possibilidades efetivas de lutas políticas por meio das quais se faz o reconhecimento dos direitos sociais e a direção do processo de formação da classe trabalhadora.

\section{Referências Bibliográficas}

ALMEIDA, Ney Luiz Teixeira de. "Apontamentos sobre a Política de Educação no Brasil hoje e a inserção dos/as assistentes sociais". In: CFESS. Subsídios para o debate sobre Serviço Social na Educação. Brasília: CFESS, 2011.

BEHRING, Elaine Rossetti. Brasil em contra-reforma: desestruturação do Estado e perda de direitos. 2.ed. São Paulo: Cortez, 2003.

BEHRING, Elaine. Trabalho e seguridade social: o neoconservadorismo nas políticas sociais. IN: BEHRING, Elaine; ALMEIDA, Maria Helena T. Trabalho e seguridade socialpercursos e dilemas. São Paulo: Cortez, 2008. 
BEHRING, Elaine Rosseti, BOSCHETTI, Ivanete. Política Social: fundamentos e história. 8.ed. São Paulo: Cortez, 2011.

CFESS. Subsídios para a Atuação de Assistentes Sociais na Política de Educação. 2013. IAMAMOTO, M. V. A questão social no capitalismo. In: Revista Temporalis. Brasília. Ano 2, n 3. p. 9-32, jan./jun.2001. (Associação Brasileira de Ensino e Pesquisa em Serviço Social - ABEPSS).

IAMAMOTO, M. V., CARVALHO, R. Relações Sociais e Serviço Social no Brasil: esboço de uma interpretação histórico- metodológica. 14a ed. São Paulo: Cortez, 2009.

MÉSZÁROS, István. Para além do capital. São Paulo: Boitempo, 2002.

NETTO, José Paulo. FHC e a política social: um desastre para as massas trabalhadoras. In: LESBAUPIN, Ivo (Org.). O desmonte da Nação - Balanço do governo FCH. Rio de Janeiro : Vozes, 1999.

Capitalismo monopolista e Serviço Social. São Paulo: Cortez, 1992.

SANTOS, Josiane Soares. Particularidades da "questão social" no Brasil: mediações para seu debate na "era" Lula da Silva. Serviço Social e Sociedade, São Paulo, n. 111, Set. 2012 Disponível em $\quad<$ http://www.scielo.br/scielo.php?script=sci_arttext\&pid=S010166282012000300003\&lng=en\&nrm=iso>, Acesso em 03 de julho de 2014. YANNOULAS, Silvia Cristina; OLIVEIRA, Talita Santos de. Avatares de Prometeu: duas décadas de avaliação e regulação das políticas educacionais. Linhas Críticas, Brasília, v. 19, n. 38 , abr. 2013. 